\title{
Laboratory Evaluation of a New Selective Water Control Treatment and its Implementation in a North Sea Well
}

\author{
* Zettlitzer M., * Schubbauer W., ** Kohler N. \\ * RWE - DEA, Germany \\ ** IFP, France
}

\begin{abstract}
Copyright 1995, Steering Committee of the European IOR - Symposium.
This paper was presented at the 8th. European IOR - Symposium in Vienne, Austria, May 16 - 17. 1995

This paper was selected for presentetion by the Steering Committee, following review of information contained in an abstract

submitted by the author(s). The paper, as presented has not been reviewed by the Steering Committee.
\end{abstract}

\section{Abstract}

In a French-German cooperation, a new weak gel consisting of a nonionic high-molecular-weight polysaccharide and an organometallic activator was developed for harsh reservoir conditions. Gel formation is delayed in surface conditions, but a gel progressively forms at reservoir temperature and selectively reduces water production, with limited effect on oil flow.

A first field application was performed on a candidate well in an oilfield in the German North Sea tidelands. The weakly consolidated, highly permeable sandstone formation with a net pay thickness of more than $30 \mathrm{~m}$ presented several streaks of more than 10 Darcies. As separation by packers was impossible, a treatment had to be designed for the entire range of the perforated interval. Moreover, the fairly high salinity of the produced brine of about $230 \mathrm{~g} / \mathrm{l}$ and the formation temperature of $70^{\circ} \mathrm{C}$ did not allow the use of standard water control chemicals. Implementation of the temperature- and salt-resistent new weak gel formulation was considered a viable alternative.

The field test was performed in June 1992. $400 \mathrm{~m}^{3}$ of $1.2 \mathrm{~kg} / \mathrm{m}^{3}$ polymer solution in formation brine were injected at a rate of $200 \mathrm{~m}^{3} / \mathrm{d}$, and $20 \mathrm{ppm}$ of the organometallic activator were added to the last quarter of the injected volume.

Production was resumed after a shut-in period of four days. The treatment was considered successful inasmuch as that the increase in water cut could be stopped at a level of $65 \%$, the overall production rate being comparable to that before treatment. However, the desired reduction in water production was not achieved, presumably because formation permeability was even higher than expected.

A laboratory post-evaluation was conducted to find out whether a possible further 
treatment with a stronger gel might be feasible. Flood tests were performed in sandpacks of very high permeability (13-17 Darcy) with different gel strengths. The results indicated that formulations yielding stronger gels would still be selective and easily injectable and would show a far greater water control potential.

\section{Introduction}

In many reservoirs, heterogeneity or bottom water coning is responsible for early water breakthrough. This results in a rapid production decline and an increase in operating costs caused by the handling and treating of large amounts of water.

Whenever possible, mechanical zone isolation or cement squeeze is usually the easiest way to shut-off the water coming from watered out layers. However, in many wells the oil- and waterproducing zones are not separated or identifiable and/or the completion mode of the well is not suitable for such workovers. In such cases, the only way to reduce water production is to inject a polymer or gel through the entire perforated interval.

The polymer or gel has to be a selective relative permeability modifier in order to reduce the risk of damaging the lower-permeability oil-bearing zones.

Polyacrylamides have been the most widely used polymers for water shut-off in production wells ${ }^{1-3}$. Alginates have also been applied successfully ${ }^{4}$. At higher temperatures, all these polymers become unstable in salt water due to hydrolysis ${ }^{5}$. Crosslinked with multivalent metal ions such as $\mathrm{Cr}^{3^{+}}$, the resulting gels are known to be more stable in harsh environments than the single uncrosslinked polymer itse $1 f^{6}$. Nevertheless, their use is not recommended in matrix reservoirs without zone isolation?

Two new polymers, a synthetic terpolymer and a nonionic polysaccharide, were recently proposed as alternatives to polyacrylamide for the treatment of high tem- perature, high salinity reservoirs ${ }^{8,9}$. Both polymers were shown to reduce selectively the relative permeability to water with little effect on the relative permeability to oil and can thus be regarded as valuable water control agents. Some field tests were already performed with each of these polymers $^{10.11}$.

A new weak gel consisting of a nonionic high-molecular-weight polysaccharide and an organometallic crosslinker was recently developed for harsh reservoir conditions ${ }^{12}$. Lab evaluation of the new system shows that it is able to selectively reduce water production with only limited effect on oil flow.

The objective of this work is to describe the methodology used in the lab to adapt the composition of a weak gel to the specific conditions of a candidate well in the North Sea and to design the treatment. Field implementation and treatment evaluation are described. A laboratory post-evaluation has helped to define criteria leading to improved water shut-off potential for a possible further treatment.

\section{Mittelplate oil field and MPA 3 well prop- erties}

The Mittelplate oilfield is located in the German North Sea tidelands. The production facilities are not installed on a platform but on an a ficial island measuring 70 by $95 \mathrm{~m}$. The reservoir consists of four oilbearing horizons (Wealden, Dogger epsiIon, Dogger delta, and Dogger beta) which, however, are not encountered in each well because of dipping. With known reserves of about 75 million metric tons OOIP, Mittelplate is one of Germany's biggest oil fields, currently accounting for a considerable share of German crude production.

Mittelplate oil production began in autumn 1987 from the wells MP 1 and MPA 2 out of Dogger beta and MPA 3 out of Dogger delta (Fig. 1). 


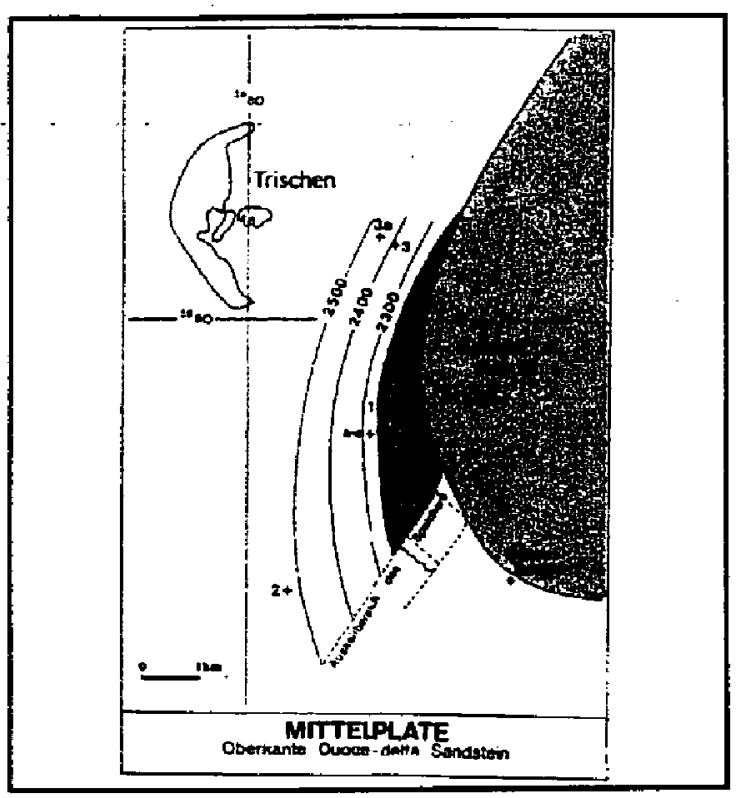

Fig. 1: Top Dogger delta Mittelplate

In order to maintain reservoir pressure in Dogger beta, water injection into MPA 5 well was started early. In the beginning, brackish water (about $20 \mathrm{~kg} / \mathrm{m}^{3}$ TDS) from water wells on the artificial island was injected, but very soon water cut in the production wells increased. The recovered brine had to be injected into MPA 5 well, because disposal of produced brine into the German North Sea is prohibited. With steadily increasing water cuts in the production wells, especially MPA 3 (Fig. 2), injection capacity of MPA 5, which so far has been the only injector on the Mittelplate island, became one of the limiting factors for Mittelplate net oil production.Thus, studies on water control treatments for MPA 3 were initiated. This well has a net pay thickness of more than 30 meters. Permeability is in the range of 3-5 Darcies, with several thin layers of more than 10 Darcies. Reservoir temperature is about $70^{\circ} \mathrm{C}$, oil gravity $19^{\circ} \mathrm{API}$ u.r.c. The water cut at a production rate of about $500 \mathrm{~m}^{3} / \mathrm{d}$ was at a level of $60 \%$ before the water control treatment (Fig. 2).

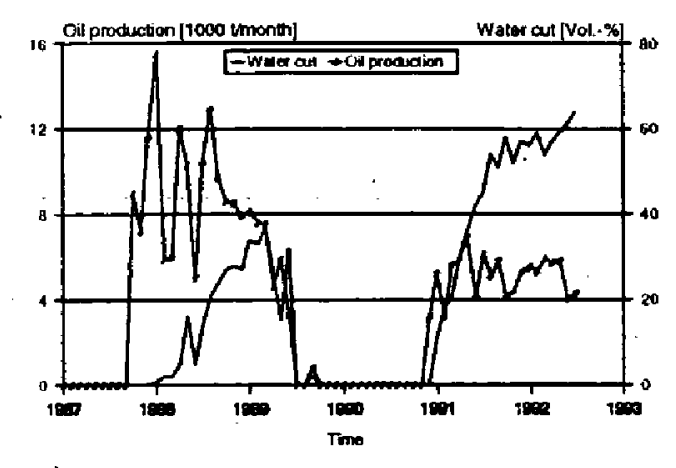

Fig. 2: Production performance of MPA 3 well before water control treatment

\section{Treatment fundamentals}

For the treatment of the well, a polysaccharide based weak-gel formulation was tested in the lab and subsequently adapted to the specific conditions of the MPA 3 well.

The polysaccharide is obtained by fermentation of glucose by fungi of the genus Sclerotinia. The powder-form polymer is manufactured by Sanofi Bio-Industries, France, under the trade name Actigum CS 11. The main characteristics of this glucantype polymer are: molecular weight $5 \times 10^{6}$ Dalton, intrinsic viscosity $7000 \mathrm{~cm}^{3} / \mathrm{g}$, molecular length $1.7 \mu \mathrm{m}$. Its rod structure gives it a strong shear-thinning rheology. Under the high-shear conditions prevailing around the wellbore, this polymer will have very low viscosities, thus promoting reduced wellhead pressures and high injection rates. At low shear rates, when the macromolecule relaxes, its hydrodynamic volume increases substantially and the polysaccharide becomes very efficient in blocking water deep inside the reservoir.

The single-polymer treatment effect is directly related to the ratio of the polymer layer thickness to the cross section of the flow. The effect of the polymer becomes negligible if the average pore radius is an order of magnitude greater than the adsorbed polymer layer thickness. Therefore, successful treatment of reservoir zones with permeabilities greater than $1 \mu \mathrm{m}^{2}$ is doubtful if the polymer is used alone. 
Polymer crosslinking is the most widely used way to improve polymer efficiency in reducing water encroachment. By controlling the crosslinking relation, gel consistency can be varied from very weak to very strong. Production well treatments without zone isolation require weak gels since they have to remain permeable to oil.

Different crosslinkers were tested to form weak gels with the nonionic glucan polymer ${ }^{12}$. The system finally retained for treatment of the well is based on the crosslinking of this polysaccharide with a non-toxic organo-zirconium complex.

The organo-zirconium complex is a zirconium lactate solution with $7 \%$ active $\mathrm{ZrO}_{2}$, manufactured by Chemical Blending Service Inc., USA.

\section{Laboratory Investigations}

The methodology used in the lab for developing and testing the polysaccharidebased weak-gel formulations consisted of the following experimental programme:

a) Determination of the polysaccharide overiapping concentration $c^{*}: c^{*}$ is the minimum concentration required for chain entanglements to occur and thus for gel to build up. This critical concentration is obtained by plotting the variation of the specific viscosity $\eta s p$ versus reduced polymer concentration $c(\eta)$ for polysaccharide solutions in brines with different salinity. For the powder form polysaccharide with intrinsic viscosity $(\eta)$ of $7000 \mathrm{~cm}^{3} / \mathrm{g}, c^{*}(\eta)$ equals 1.5 and $c^{\star}=210 \mathrm{ppm}$ (Fig. 3). The polymer being nonionic, $C^{*}$ is insensitive to the ionic environment.

b) Establishment of the sol/gel diagram: Figure 4 shows the sol/gel diagrams obtained at $30^{\circ} \mathrm{C}$ and $80^{\circ} \mathrm{C}$, respectively, for

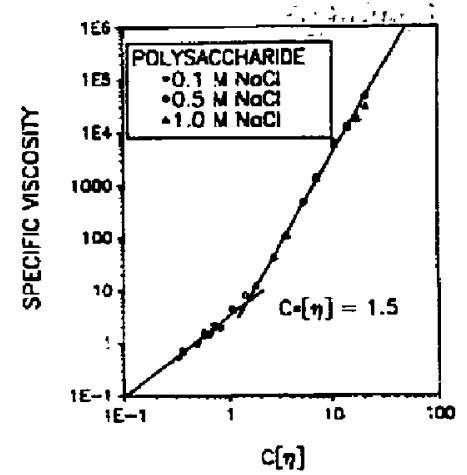

Fig. 3: Determination of polymer overlapping concentration $\mathrm{C}^{*}$

different concentrations of polysaccharide and organo-zirconium complex in a $0.5 \mathrm{M}$ $\mathrm{NaCl}$ solution. It should be noted that, although the gel zones are quite similar, the diagram at $30^{\circ} \mathrm{C}$ was established after 7 days, while that at $80^{\circ} \mathrm{C}$ was taken after 24 hours.
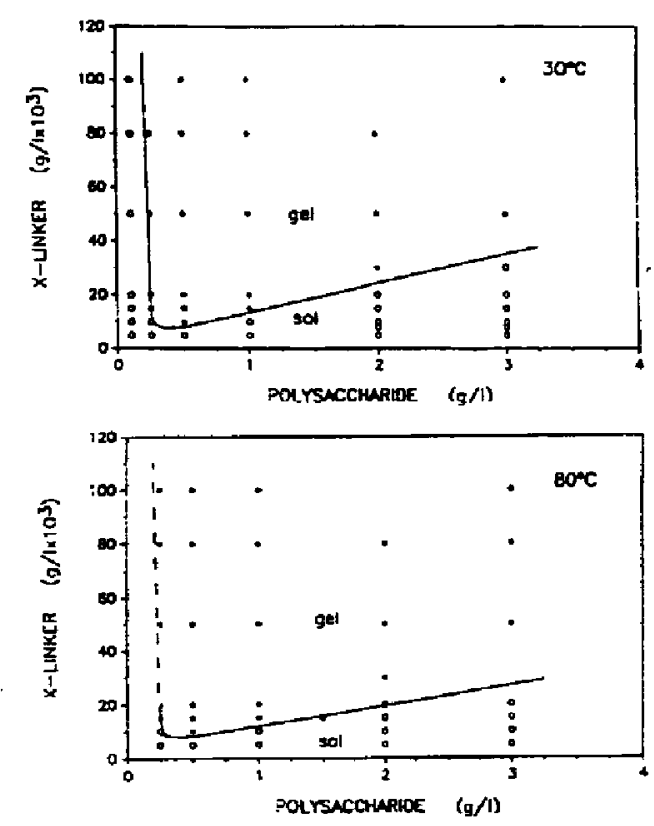

Fig. 4: Phase diagram at $30^{\circ} \mathrm{C}$ and $80^{\circ} \mathrm{C}$ of crosslinker/polysaccharide gelling system

c) Kinetics of gel formation: The gel system. thus is temperature and also $\mathrm{pH}$ dependent.

Figure 5 shows, for example, the evolution with time of the elastic modulus $G^{\prime}$ at different temperatures for a 1500 ppm polysaccharide and 100 ppm crosslinker mixture in 
a $0.5 \mathrm{M} \mathrm{NaCl}$ brine. For a fixed polymer/crosslinker concentration, gelation kinetics increase with temperature. If necessary, retarding chelating agents may be added in order to delay gel formation for 24 hours or more.

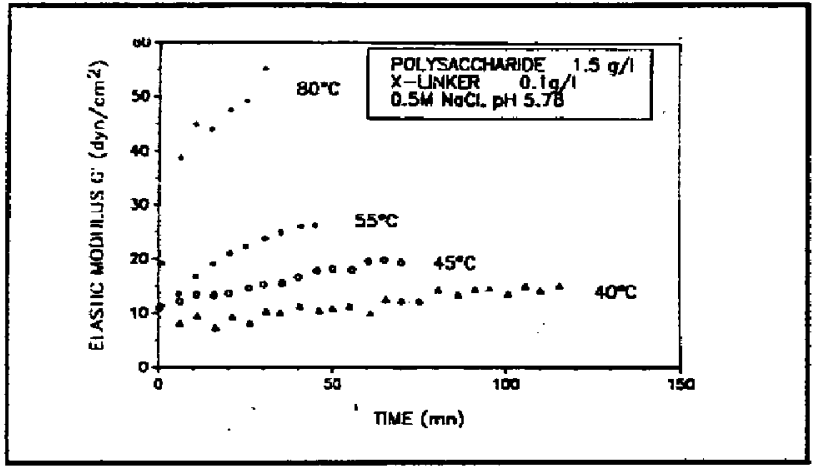

Fig. 5: Crosslinker/polysaccharide gelling kinetics at different temperatures

At room temperature and in neutral $\mathrm{pH}$ conditions, gelation is delayed, while, at reservoir temperature, gel forms in neutral or slightly acidic conditions. Premature gel formation in surface facilities is therefore prevented.

d) Effect of polymer and gel on oil/water relative permeabilities: In order to evaluate their effect on oil and water relative permeabilities, comparative core tests were performed on a high-permeability Vosges sandstone $\left(k=1,20 \mathrm{\mu m}^{2}\right)$ at $95^{\circ} \mathrm{C}$. First, the core was flushed with polysaccharide solution in a $20 \mathrm{~g} / \mathrm{L} \mathrm{KCl}$ brine and the corresponding relative permeability values were measured. Thereafter, a weak gel containing $1500 \mathrm{ppm}$ polysaccharide and $20 \mathrm{ppm}$ of the organo-zirconium complex was injected and the core was shut-in for 16 hours at $95^{\circ} \mathrm{C}$.

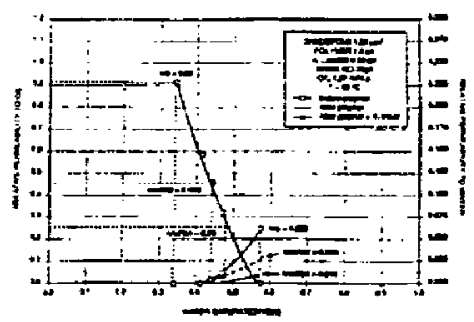

Fig. 6: Effect of Actigum alone and of crosslinker/Actigum weak gel on relative permeabilities
Figure 6 shows that the weak gel is more effective than the single polymer in selectively reducing the permeability to water. The performance of the weak gel is rather promising:-permeability to water decreases by a factor of 5 , while relative permeability to oil remains unaffected.

Additional tests were initiated to develop a proper treatment design for the Mittelplate reservoir:

- Polymer compatibility with clarification brine

The formation to be treated in MPA 3 well is Dogger delta with high formation water salinity of $230 \mathrm{~kg} / \mathrm{m}^{3}$ TDS, with $170 \mathrm{mg} / \mathrm{l}$ borate, and $35 \mathrm{mg} / \mathrm{l}$ ferrous ions. Storage of this brine for mixing water purposes had to be avoided because of its tendency to form insoluble ferric hydroxide and similar precipitates upon contact with air. Thus, Dogger beta clarification brine with a water salinity of $120 \mathrm{~kg} / \mathrm{m}^{3}$ (Table 1), which was available at a rate of about $200 \mathrm{~m}^{3} / \mathrm{d}$, was used to prepare the polymer solution. In view of the composition of the two brines, compatibility of polymer with mixing and formation water was checked.

\begin{tabular}{|c|c|c|c|c|}
\hline $\begin{array}{l}\text { Water } \\
\text { type }\end{array}$ & $\begin{array}{l}\text { Salinity } \\
\text { [\$/ TDS] }\end{array}$ & $\begin{array}{l}\text { Borale } \\
\text { [mgl } \mathrm{BO}_{2}- \\
1\end{array}$ & $\begin{array}{l}\text { Ferrous } \\
\text { ions } \\
\text { [mg/l] }\end{array}$ & $\begin{array}{l}\text { First } \\
\text { newt. } \\
\text { plateau }\end{array}$ \\
\hline $\begin{array}{l}\text { Dogger } \\
\text { delta }\end{array}$ & 230 & 170 & 35 & 4780 \\
\hline $\begin{array}{l}\text { Dogger } \\
\text { delta }\end{array}$ & 230 & 170 & $<0,5$ & 2770 \\
\hline $\begin{array}{l}\text { Dogger } \\
\text { bela }\end{array}$ & 120 & 25 & 0 & 1210 \\
\hline $\begin{array}{l}140 \text { gA } \\
\text { TDS }\end{array}$ & 140 & 0 & 0 & 283 \\
\hline
\end{tabular}

Table 1: Gelation of Actigum in Mittelplate clarification brines

While viscosity curves measured in the above mentioned waters at shear rates between 0.5 and $200 \mathrm{~s}^{-1}$ do not differ significantly, viscosity at very low shear 
stresses ranges from almost $5000 \mathrm{mPa} . \mathrm{s}$ in Utnitreated Dogger delta brine to only about $300 \mathrm{mPa}$.s in $140 \mathrm{~kg} / \mathrm{m}^{3}$ TDS brine (Table 1). This is an indication of the formation of a weak gel in all the waters containing borate and/or ferrous ions. The gel particles could also be visually detected in the solutions and in a constant-rate injectability test: The pressure across the sandpack rose when gel particles temporarily plugged the front and fell when the deformable gel particles finally entered the sandpack under increasing injection pressure (Fig. 7).

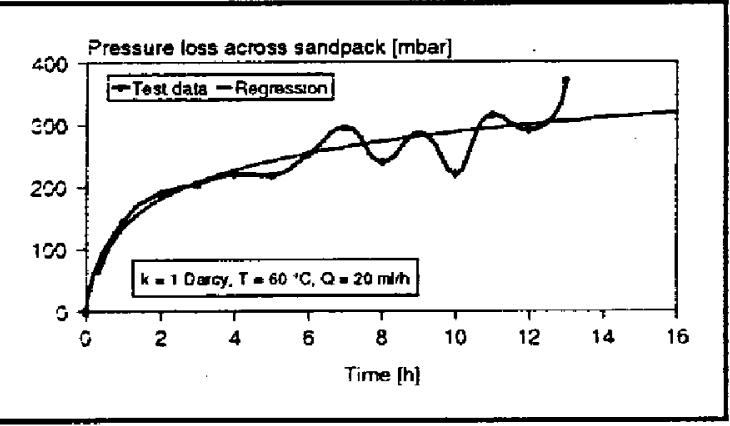

Fig. 7: Injectability of $1 \mathrm{~g} / \mathrm{l}$ Actigum in Dogger delta clarification brine

Altogether, the injectability of even the strongest of the above-mentioned weak gels is good under the test conditions ( $k=1$ Darcy, $\mathrm{T}=60^{\circ} \mathrm{C}$ ).

- Reaction kinetics of polymer and activator

It had been shown that the organometallic activator is salted out in the highly saline mixing water within about one hour. Thus, it had to be checked, whether the competing reaction of polymer and activator is faster.

Kinetics of the reaction of Actigum with the activator (in concentrations of $0,20,30$, 40 , and $50 \mathrm{ppm}$, respectively) in clarification brine were studied. At $25^{\circ} \mathrm{C}$, no gelation occurs with the activator within two days, so that surface premixing of polymer and activator should not cause problems.

At $70^{\circ} \mathrm{C}$, a fast gelation reaction can be visually detected. At extremely low shear rates, corresponding to extremely low shear stresses, the viscosity of the sollution without activator increases by a factor of seven, indicating the (re)formation of polymer overstructures after the high-shear mixing. The activator in concentrations of 30 and $50 \mathrm{ppm}$, respectively, leads to a viscosity increase by a factor of 14 and 25 , respectively, thus quantitatively confirming the formation of a gel in the presence of activator (Fig. 8).

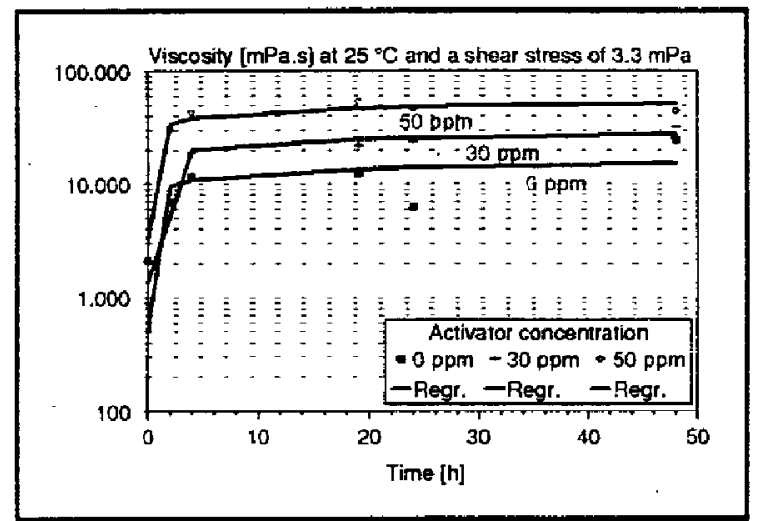

Fig. 8: Reaction of $1 \mathrm{~g} / \mathrm{l}$ Actigum in brine with Zr-lactate at $70^{\circ} \mathrm{C}$

The reaction is fast and more or less complete within four hours and, contrary to the compatibility tests of activator and clarification brine described before, the activator is not salted out.

The gel obtained with 50 ppm activator is still injectable, though the pressure drop across the sandpack is much greater than without activator (Fig. 9).

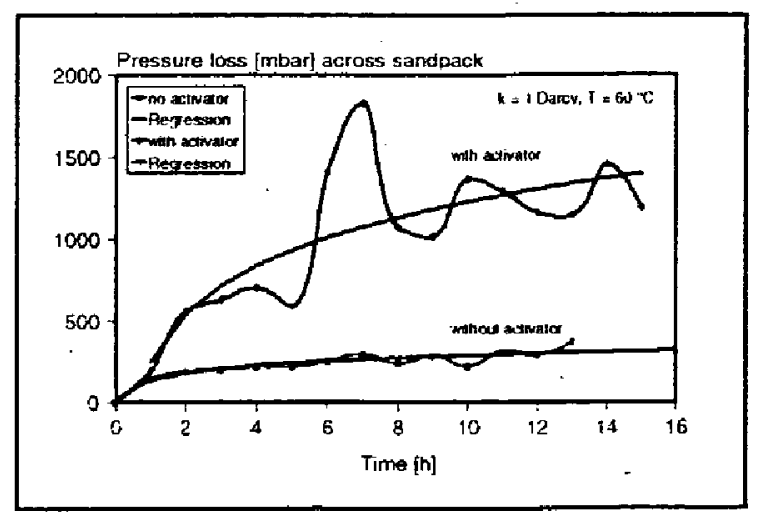

Fig. 9: Injectability of $1 \mathrm{~g} /$ / Actigum in brine with and without $\mathrm{Zr}$-lactate 
Treatment implementation and evaluation

At the end of June 1992, the Mittelplate A3 well was treated with Actigum solution. Based on laboratory investigations, polymer mixing was performed in two steps: First, a stock solution was prepared onshore in an existing polymer mixing plant from a former flood project. In a second step, the stock solution was diluted to final concentration on the Mittelplate island.

\section{- Preparation of stock solution}

Tap water was treated with formaldehyde and used for stock solution mixing. Altogether, seven batches with a total volume of $48 \mathrm{~m}^{3}$ and a concentration of $10 \mathrm{~kg} / \mathrm{m}^{3}$ Actigum were prepared. The polymer was dosed by means of a screwconveyor, passed a disperser and was then dissolved in the prepared mixing water. The solution was stirred for about two hours, sheared through shear plates and pumped into two connected transportation tanks.

The different batches of the stock solution were all very homogeneous and yielded viscosities comparable to that of a labmixed stock solution in fresh water. Only the last batch, which had to be mixed in a somewhat higher concentration because of limited transportation capacity. had a slightly higher viscosity. The gas phase of the tanks was filled with nitrogen in order to retard slow oxidative degradation.

\section{- Preparation of diluted Actigum solution} and injection into MPA 3 well

Prior to the treatment, an injection test on MPA 3 was carried out with a total of 30 $\mathrm{m}^{3}$ brine. Injection could be performed with rates between 70 and $215 \mathrm{~m}^{3} / \mathrm{d}$ at zero wellhead pressure. Thereafter, $400 \mathrm{~m}^{3}$ of $1.2 \mathrm{~kg} / \mathrm{m}^{3}$ Actigum solution were continously prepared from polymer stock solution and Dogger beta brine and injected. Well- head pressure remained constant at about 11 bar at a rate of $200 \mathrm{~m}^{3} / \mathrm{d}$.

Solution viscosity was regularly checked and came up to the same order as labmixed solutions.

At the end of the injection period, $20 \mathrm{ppm}$ zirconium lactate was added to the ACtigum solution. Wellhead pressure remained constant. Polymer injection was followed by a small brine spacer $\left(5 \mathrm{~m}^{3}\right)$ and by $15 \mathrm{~m}^{3}$ Diesel (1.5 times the tubing volume). During Diesel injection, wellhead pressure rose to 50 bar.

After treatment, the well was shut in for four days.

- Analysis of effluents and production results of MPA 3 well after water control treatment

Production from MPA 3 was resumed on June 29, 1992. The light Diesel column that had been placed into the tubing after treatment allowed eruptive production, which could be maintained even when the water cut and, concurrently, specific weight of the column increased. During the first two days, mainly the injected Dogger beta clarification brine that had been used to mix the Actigum solution was produced back (Fig. 10).

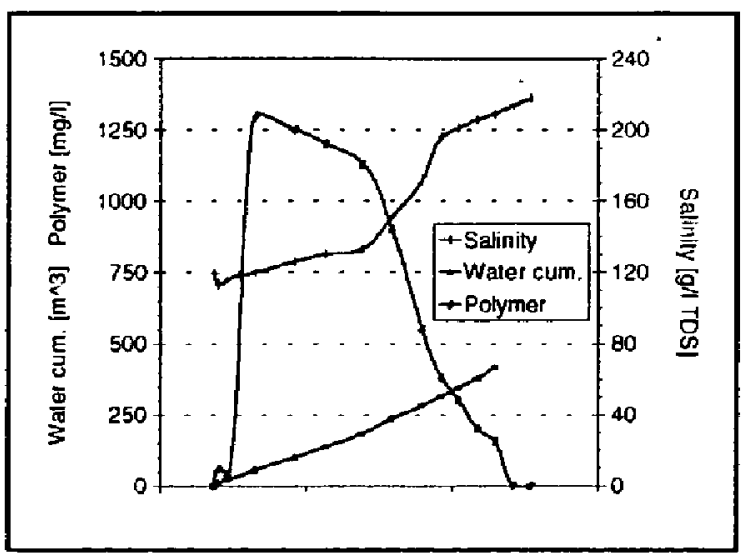

Fig. 10: Polymer and salinity in wet oil water phase of MPA 3 after production restart

About 60 per cent of the Actigum injected was produced back as could be calculated 
from viscometric and photometric (phenol/sulfuric acid) polymer determination.

After two days, the injected brine volume had been produced back, and oil cut had increased to 50 per cent. The column became lighter again and the production rate rose. Figure 11 compares production rate and water cut before and after chemical treatment.

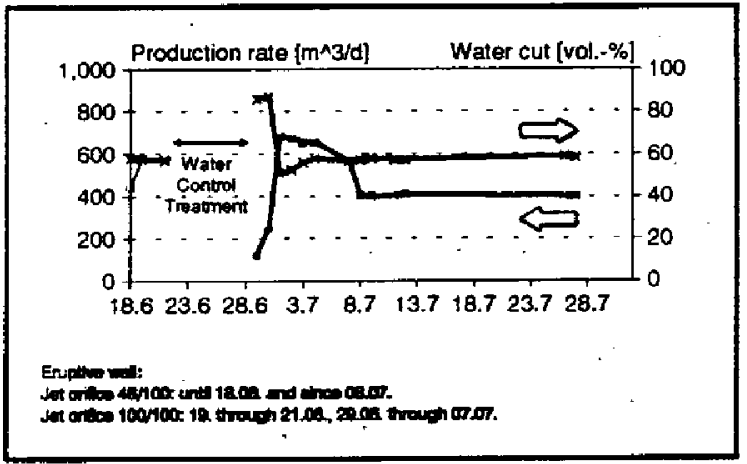

Fig. 11: Water cut and production rate immediately before and after MPA 3 treatment

Until June 18, 1992, the well had eruptively been produced with a jet orifice of $46 / 100$. On June 19, jet orifice was increased to $100 / 100$ for three days. As a consequence, the production rate increased. After the treatment, the well was produced with fully open nozzle until July 7 , from then on again with $46 / 100$.

Separator measurements could only be performed until the end of July 1992. From then on, water cut was determined by means of volumetric determination in wellhead samples. There are slight differences in the results obtained by analytical means and those yielded by separator measurements, but the tendency is the same. As outlined above, a continuous increase in water-cut was observed until the beginning of treatment in June 1992. From then on for about 18 months, water-cut was more or less stable at about 65 volume per cent (Fig. 12) at a production rate comparable to that before treatment. Thereafter, water cut slowly increased again.

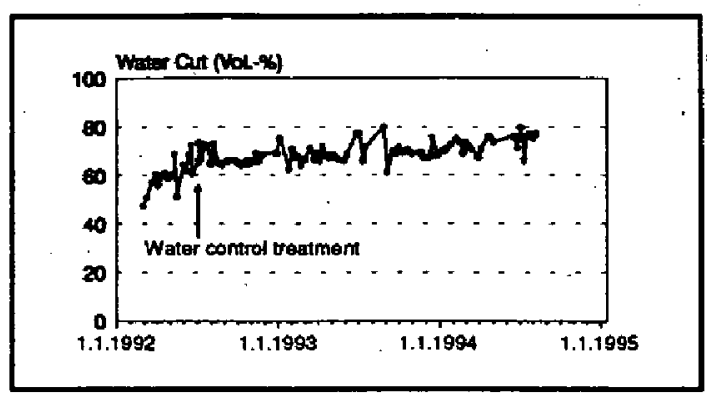

Fig. 12: Water cut of MPA 3 before and after water control treatment

\section{Post-treatment investigations}

As mentioned above, the wellhead pressure remained constant during field treatment and a considerable amount of the polymer injected was produced back. Possibly, the permeability of the water bearing streaks was even higher than expected.

In order to find out whether a treatment with a higher gel strength might have been feasible and more efficient, several flood tests on sandpacks with a very high permeability (13-17 Darcies) were performed in Dogger beta clarification brine (containing $85 \mathrm{mg} / \mathrm{l}$ borate) at a temperature of 70 ${ }^{\circ} \mathrm{C}$. White oil with a viscosity similar to that of Mittelplate Dogger delta crude was used as oil phase. Two pore volumes of Actigum with $\mathrm{Zr}$-lactate concentrations between 0 and $200 \mathrm{ppm}$ were injected, sandpacks were shut in for about four days and relative permeability curves were determined before and after treatment.

The results are summarized as follows:

- At permeabilities as high as in these tests, treatments with activator concentrations up to $20 \mathrm{ppm}$ yield a decrease in water permeability by a factor of about three.

- With higher activator concentrations, water permeability can be considerably reduced and treatment efficiency correlated to activator concentration (Fig. 13). The rate dependence is not very pronounced. 


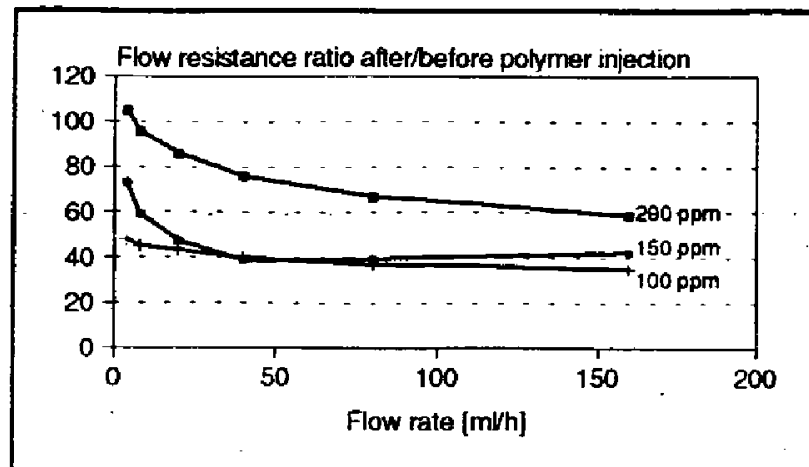

Fig. 13: Reduction of water permeability vs. Zr-lactate concentration

- The relative permeability to oil is decreased to a lesser extent, so that a sufficient oil permeability can be preserved. In these tests, the remaining effective oil permeability at $S_{w i}$ amounts to at least 1500 mo.

- No polymer was detected in the effluent in the postflush phase and flow resistance to water remained constant even after production of several pore volumes. The gel formed by injection of the chemicals is strong enough to remain in the pore space at fairly high Darcy velocities (up to 20 $\mathrm{m} / \mathrm{d}$ ).

\section{Conclusions}

1. A new chemical system for water control in harsh environments and high permeability formations was developed.

2. Gel formation at surface conditions is very slow, permitting easy chemical mixing, while at reservoir temperature a weak- to medium-strength gel progressively forms.

3. A selective reduction of water permeability with minor effect on oil permeability is achieved.

4. A field application in an offshore well was successful inasmuch as water cut increase could be stopped.
5. Laboratory post-evaluation yielded chemical systems for extremely high permeabilities.

\section{Acknowledgments}

This research was supported by EEC-Contract No. 03-307/89.

\section{References}

1. Sparlin, D.D. and Hagen, R.W.: "Controlling Water in Producing Operations, Part 5: Using Polyacrylamide Polymers", World Oil (July 1984), 137-142.

2. Zaitoun, A., Kohler, N. and Guerrini, Y.: "Improved Polyacrylamide Treatments for Water Control in Producing Wells", JPT (July 1991), 862-867.

3. Seright, R.S. and Liang, J.: "A Survey of Field Applications of Gel Treatments for Water Shutoff", paper SPE 26991 presented at the 1994 SPE Permian Basin Oil \& Gas Recovery Conference, Midland, TX, March 16-18.

4. Zettlitzer, M., Schuhbauer, W. and Volz, H.: "Laboratory Preparation and Field Application of a Chemical Water Shut-Off Treatment", 7th European Symposium on Improved Oil Recovery, Moscow, October 27-29, 1993.

5.Moradi-Araghi, A. and Doe, P.A.: "Hydrolysis and Precipitation of Polyacrylamides in Hard Brines at Elevated Temperatures", SPE Reservoir Engineering (May 1987), 189-198.

6. Sydansk, R.D.: "Acrylamide-Polymer/Chromium (III) - Carboxylate Gels for Near Wellbore Matrix Treatments", paper SPE 20214 presented at the SPE/DOE Seventh Symp. on EOR, Tulsa, OK, April 22-25, 1990. 
7. Liang, J; Lee, R.L. and Seright, R.S.: "Gel Placement in Production Wells", SPE Production \& Facilities (No. 1993), 276284.

8.Zaitoun, A., Kohler, N., Maitin, B.K., and Zettlitzer, M.: "Preparation of a Water Control Polymer Treatment at Conditions of High Temperature and Salinity" Journal of Petroleum Science and Engineering, 7, 6775, 1992.

9. Kohler, N. and Zaitoun, A.: "Polymer Treatment for Water Control in High-Temperature Production Wells", paper SPE 21000 presented at the SPE International Symposium on Oilfield Chemistry, Anaheim, CA, February 20-22, 1991.

10. Gruenenfelder, M.A., Zaitoun, A., Kohler, N., Ali, S.A. and Linser, T.M.: "Implementing New Permeability Selective Water Shutoff Polymer Technology in Offshore, Gravel-Packed Wells", paper SPE/DOE 27770 presented at the SPE/DOE Ninth Symp. on IOR, Tulsa, OK, April 17-20, 1994.

11. Ranjbar, Mr., Czolbe, P. and Kohler, V.: "Comparative Laboratory Selection and Field Testing of Polymers for Selective Control of Water Production Gas Wells", paper SPE 28984 presented at the SPE International Symposium on Oilfield Chemistry, San Antonio, TX, February 14-17, 1995.

12. Kohler, N., Rahbari, R., Han, M. and Zaitoun, A.: "Weak-Gel Formulations for Selective Control of Water Production in High-Permeability and High-Temperature Production Wells", paper SPE 25225 presented at the SPE International Symposium on Oilfield Chemistry, New Orleans, LA, March 2-5, 1993. 